\title{
Percutaneous Vertebroplasty for the Treatment of Osteoporotic Thoracolumbar Fractures with Posterior Body Involved in Elderly Patients
}

\author{
Kerem Mazhar OZSOY ${ }^{1}$, Kadir OKTAY ${ }^{2}$, Yurdal GEZERCAN ${ }^{3}$, Nuri Eralp CETINALP ${ }^{1}$, Ali Ihsan OKTEN ${ }^{3}$, \\ Tahsin ERMAN ${ }^{1}$ \\ ${ }^{1}$ Cukurova University, Faculty of Medicine, Department of Neurosurgery, Adana, Turkey \\ ${ }^{2}$ Gaziantep Medical Park Hospital, Neurosurgery Clinic, Gaziantep, Turkey \\ ${ }^{3}$ Adana Numune Training and Research Hospital, Department of Neurosurgery, Adana, Turkey
}

Early results of this study were presented as an oral presentation at the Turkish Neurosurgical Society Lumbar Degenerative Spine Symposium, 20-23 October 2017, Antalya, Turkey.

\section{ABSTRACT}

AIM: To present the results of vertebroplasty for treating thoracolumbar burst fractures without neurological deficit.

MATERIAL and METHODS: Twelve patients (aged $\geq 65$ years) with thoracolumbar fractures but without neurological deficits underwent vertebroplasty. In all fracture cases, the anterior and middle columns of the vertebrae were affected and the canal was mildly compressed. To assess the clinical symptoms and the effects of the procedure, patient mobility and pain were assessed prior to the procedure and at 1 day and 3 months after the procedure.

RESULTS: Improvements in pain and mobility were observed immediately after vertebroplasty in all patients. These results were observed for 3 months. Significant improvements were also noted at 1 day and 3 months after vertebroplasty. Pain was reduced by at least 4 levels after 3 months. No co-morbidities were observed. However, computed tomography revealed polymethylmethacrylate leakage through the endplate fracture site into the disc space or paravertebral space in four vertebrae and minimal intracanal leakage through the fracture line in one patient.

CONCLUSION: Vertebroplasty is assumed to be contraindicated in patients with osteoporotic thoracolumbar fractures with posterior body involvement. However, this procedure was successfully performed to safely treat such fractures without causing neurological deficits. Percutaneous vertebroplasty may be an alternative method for treating thoracolumbar burst fractures that prevents major surgical complications. Moreover, it helps patients achieve early mobilization and pain relief.

KEYWORDS: Middle column, Percutaneous vertebroplasty, Posterior wall, Spinal fracture

\section{INTRODUCTION}

$\mathrm{G}$ alibert and Deramond first performed percutaneous vertebroplasty (PV) in 1984 by injecting polymethylmethacrylate (PMMA) into the $\mathrm{C} 2$ vertebra that had been destroyed by an aggressive hemangioma (2). PV began to be performed more frequently after Lapras et al. demonstrated in 1989 that this operation could treat pain caused by compression fractures (9). This procedure is primarily used to treat osteoporotic compression fractures as well as localized osteolytic metastatic vertebral tumors and myelomas.

The treatment of patients with thoracolumbar fracture without neurological deficit is controversial. Conservative treatment and bed rest have traditionally been the only treatment options for such fractures, particularly in cases involving elderly 
patients and/or patients who are at a high risk for operation because of co-morbidities. In 2002, Nakano et al. performed percutaneous transpedicular vertebroplasty to treat patients with thoracolumbar burst fractures without neurological deficit; since this initial procedure, highly successful results have been obtained by this treatment (11). Because of the effectiveness of vertebroplasty in patients with vertebral osteoporotic fractures, we used this procedure to treat patients with middle column fractures without neurological deficit.

\section{MATERIAL and METHODS}

\section{Patient Selection}

The selected patients were limited to individuals with acute, focal, severe, and intractable pain at the levels of their vertebral fractures and with the involvement of the posterior wall as well as those without neurological symptoms who underwent vertebroplasty between May 2012 and March 2015 (Figure 1).

All patients were older than 65 years. Demographic data, including age, gender, and fracture level, were recorded. Patients' fractures were classified according to the Denis classification. All patients underwent computed tomography (CT) scan, plain radiography, and bone densitometry test. The radiological inclusion criterion was the involvement of the posterior wall of vertebral body.

\section{Visual Analog Scale and Mobility Index}

To assess their clinical symptoms and the effect of the procedure, all patients underwent pain evaluation using the visual analog scale (VAS; $0=$ no pain, $10=$ maximum pain) prior to the procedure as well as at 1 day and 3 months after the procedure. Patient mobility was assessed according to the following scale: $0=$ walking without assistance, $1=$ =walking with assistance, 2=wheelchair-bound, $3=$ activities restricted to sitting in bed, and $4=$ activities restricted to lying flat in bed.

\section{Surgical Technique}

The median time between the fractures and surgeries was 3 days. All procedures were performed in an operating room using C-arm fluoroscopy. Vertebroplasty was performed under local anesthesia with a moderate degree of conscious sedation. The patient was placed in the prone position with the arms raised above the head. The fractured vertebrae and their respective landmarks were identified on fluoroscopy. The unipedicular transpedicular approach was used for all patients. PMMA cement was mixed until it reached the consistency of toothpaste and was then slowly injected. The density of the cement was higher than that of the cement used for classical vertebroplasty. We attempted to completely fill the anterior two-thirds of the vertebrae with cement.

\section{Statistical Analysis}

For data analysis, Friedman's two-way analysis of variance by ranks for related samples was used to compare medians instead of means because the study data did not meet the parametric test criteria. A post hoc analysis with Wilcoxon signed-rank tests was conducted, and the Bonferroni correction was applied. A $p$ value of $<0.05$ was considered statistically significant.

\section{RESULTS}

Vertebroplasty was performed in 12 patients $(6$ women and 6 men) who presented with fractured vertebrae with posterior wall involvement. The mean age of the patients was 74 years (Table I). According to the Denis classification, 11 patients had two-column fractures and 1 had a three-column fracture.

The vertebroplasty procedures were successful in all patients. In four patients, the cement leaked outside the vertebrae (2 patients with leakage into the intervertebral disc space, 1 patient with paravertebral leakage, and 1 patient with minimal leakage through the posterior wall). All patients exhibited clinically unremarkable extravasation. No patient required a secondary surgical intervention.

Compared with the corresponding metrics preoperatively, both VAS scores and mobility indices were significantly low immediately postoperatively and remained significantly low at 3 months postoperatively in all patients $(p<0.001)$.

\section{DISCUSSION}

The goals of treatment for thoracolumbar burst fractures include early patient mobilization and the acquisition of a painless, balanced, and stable vertebral column with maximum spine mobility and optimum neurological function. The management strategies for these fractures include but are not limited to conservative (non-operative) therapy, isolated posterior stabilization (with or without decompression), isolated anterior decompression and stabilization, and either vertebroplasty or kyphoplasty.

Burst fractures may cause significant pain that adversely affects the patient's mobility and quality of life. The conservative treatment of vertebral osteoporotic burst fractures includes bed rest (in combination with other activity modifications), bracing, and use of analgesics. Patients are commonly assessed for osteoporosis and are prescribed calcium, vitamin $\mathrm{D}$, calcitonin, and bisphosphonates. Among elderly patients, inactivity and immobility are independently associated with the increased rates of pneumonia, decubitus ulcers, venous thromboembolism, and death $(3,4,12,13)$. In addition, analgesics are not well tolerated by elderly patients, and brace application may be extremely troublesome because of poor patient compliance.

In the literature, the surgical treatment of burst fractures has generally been indicated for patients with either neurological deficits or severe instability, including kyphotic deformities $>30^{\circ}$ at the fracture level, canals that are $>50 \%$ compromised, and vertebral body height losses of $>50 \%(1,7)$. However, surgical treatment possibilities are limited in elderly patients because of decreased bone quality.

In most cases involving burst fractures, an open procedure is not indicated because of the aforementioned risks. The development of minimally invasive surgery has provided surgeons and patients with good treatment alternatives to such procedures. During the first decade of this century, PV was introduced in clinical practice as a minimally invasive treatment for thoracolumbar burst fractures in patients with 
Table I: Demographic Characteristics of the Patients

\begin{tabular}{|c|c|c|c|c|c|c|}
\hline Patient & $\begin{array}{l}\text { Age (years)/ } \\
\text { Gender }\end{array}$ & Fracture Level & $\begin{array}{l}\text { Preoperative } \\
\text { VAS score }\end{array}$ & $\begin{array}{l}\text { Postoperative } \\
\text { VAS score: } \\
\text { 1 Day/3 Month }\end{array}$ & $\begin{array}{l}\text { Preoperative } \\
\text { Mobility Index }\end{array}$ & $\begin{array}{l}\text { Postoperative } \\
\text { Mobility Index: } \\
1 \text { Day/3 Month }\end{array}$ \\
\hline 1 & $86 / M$ & T9 & 10 & $7 / 6$ & 4 & $2 / 2$ \\
\hline 2 & $73 / \mathrm{M}$ & T11 & 10 & $7 / 3$ & 4 & $2 / 1$ \\
\hline 3 & $65 / F$ & T11 & 8 & $6 / 2$ & 3 & $2 / 1$ \\
\hline 4 & $96 / M$ & $\mathrm{~T} 12$ & 7 & $4 / 1$ & 1 & $1 / 0$ \\
\hline 5 & $71 / \mathrm{F}$ & $\mathrm{T} 12$ & 8 & $5 / 2$ & 2 & $1 / 0$ \\
\hline 6 & $67 / M$ & L2 & 8 & $6 / 1$ & 2 & $1 / 0$ \\
\hline 7 & $75 / M$ & $\mathrm{~T} 11$ & 7 & $5 / 1$ & 1 & $1 / 0$ \\
\hline 8 & $81 / F$ & $\mathrm{~T} 12$ & 7 & $4 / 1$ & 2 & $1 / 0$ \\
\hline 9 & $69 / F$ & $\mathrm{~T} 12$ & 8 & $5 / 1$ & 2 & $1 / 0$ \\
\hline 10 & $71 / \mathrm{M}$ & L1 & 7 & $5 / 2$ & 2 & $1 / 0$ \\
\hline 11 & $76 / F$ & T10 & 7 & $4 / 1$ & 1 & $1 / 0$ \\
\hline 12 & $67 / F$ & L1 & 8 & $5 / 2$ & 2 & $1 / 0$ \\
\hline
\end{tabular}

VAS: Visual analog scale, M: Male, F: Female, T: Thoracic, L: Lumbar.

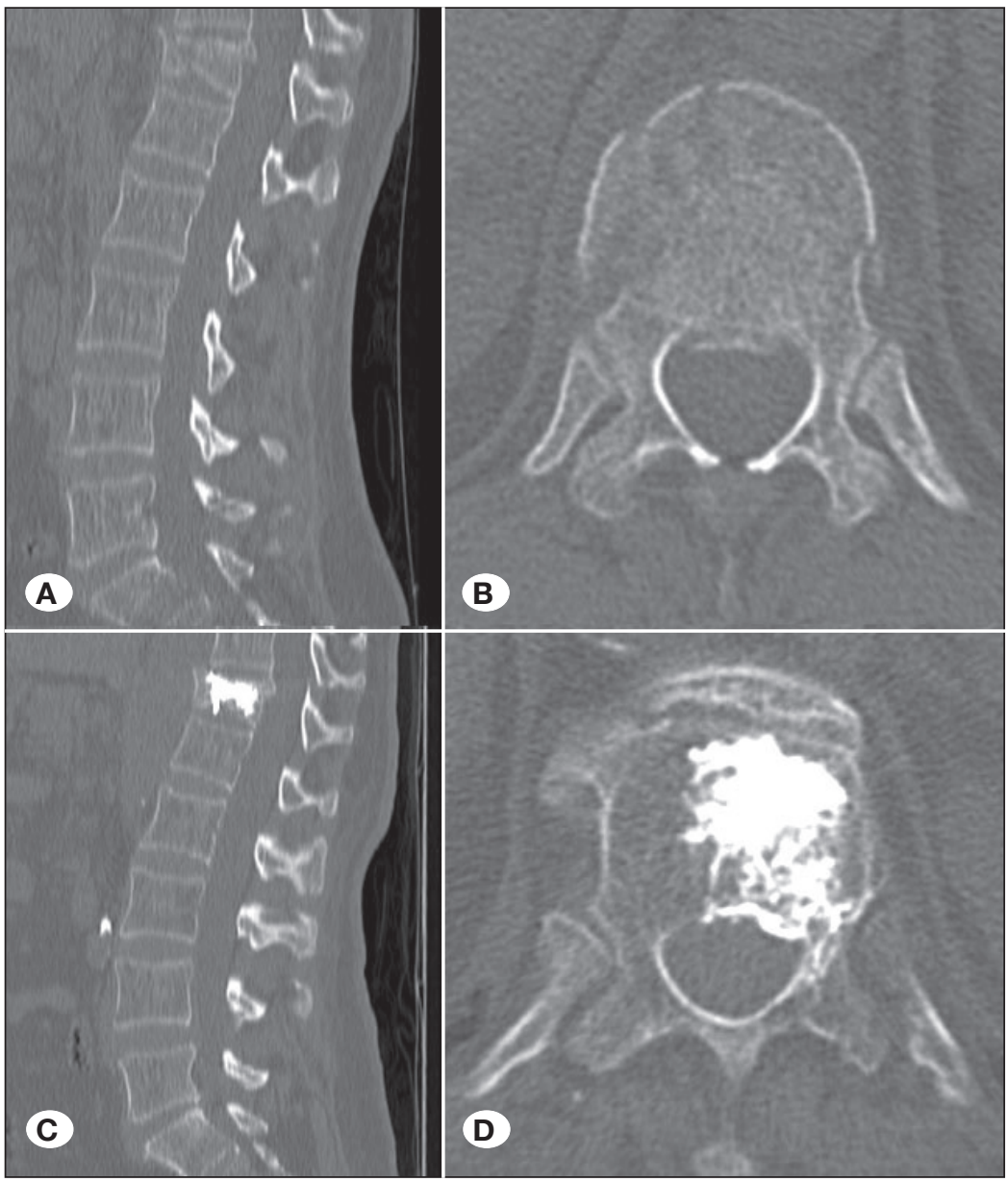

Figure 1: A) Sagittal and B) axial computed tomography (CT) image revealing T12 vertebra fracture and minimal narrowing in the spinal canal. Postoperative sagittal CT images C) after vertebroplasty depicting the cement filling the T12 vertebral body. D) Axial CT image after vertebroplasty revealing minimal cement leakage through the fractured tract. No prominent worsening of the retropulsion was observed. 
intact neurological function. However, the use of vertebroplasty in these cases remains controversial. Some studies have suggested that retropulsed fragments and enhancements in the central spinal canal are contraindications for vertebroplasty due to the risk of further damage in the spinal canal. However, various studies have shown that vertebroplasty may be safely used to treat thoracolumbar burst fractures $(5,6,8,15)$. We performed vertebroplasty in elderly patients with spinal canal narrowing and observed improvements in terms of patient symptoms and pain.

Hiwatashi et al. examined 21 consecutive patients and showed that vertebroplasty may be used safely even in patients with retropulsed fragments (5). In patients without significant neurological deficits, the correction of kyphotic deformities and restoration of vertebral body height significantly reduced VAS scores and increased mobility despite the presence of retropulsed fragments. In 25 consecutive patients, Shin et al. investigated clinical outcomes, kyphosis correction, wedge angles, and height restoration in the context of thoracolumbar osteoporotic burst fractures treated with postural reduction followed by vertebroplasty. Kyphotic angles, wedge angles, and anterior, middle, and posterior heights significantly improved after these procedures; however, clinical deterioration was not discussed (15). Krüger et al. described a series of 97 incomplete osteoporotic burst fractures treated with kyphoplasty. Moreover, significant improvements were observed in terms of VAS scores and the patients did not present with neurological complications (8).

Cement leakage is the most significant potential complication of vertebroplasty. In our study, 4 of the 11 examined patients exhibited cement extravasation. In the literature, extravasation rates range from $45 \%$ to $80 \%$ (14). With respect to vertebroplasty for thoracolumbar burst fractures, studies have indicated that cement leakage most commonly occurs in either the paravertebral tissues or the disk space; however, none of the described patients developed neurological deficits $(5,6,8,15)$.

Various types of cement may be used for vertebroplasty and kyphoplasty; PMMA and calcium phosphate cement are used most frequently for these procedures (10). In PV, PMMA is the primary cement used to treat thoracolumbar fractures. Relative to calcium phosphate cement, PMMA is easier to apply because it has lower viscosity and therefore can be more readily applied in controlled quantities. The disadvantages of PMMA cement include the requirement for an exothermic reaction during polymerization and the inability to facilitate new bone growth because of heat disclosure and lack of bioactivity. PMMA cement is not an ideal material for thoracolumbar burst fractures. However, various studies addressing its use have associated its application with significant improvements in VAS scores. Moreover, the stabilization of microfractures, the manual reduction of mechanical stress prior to vertebroplasty, the loss of mechanical stress due to decreased kyphotic angles, and the anti-inflammatory effects of its cytotoxicity and thermal activity are factors that can relieve pain (10).

In this study, significant improvements in VAS scores were observed immediately after vertebroplasty, and these improvements increased during the follow-up period. In a similar study, Huet et al. did not describe any instances of reoperation, with the exception of simultaneous procedures on two adjacent fractured vertebra segments (6). In the current study, re-operation was performed because of increased kyphotic angles observed during the follow-up period rather than because of pain.

This study has several limitations. The primary limitation is the lack of long-term follow-up among patients. Long-term complications, such as adjacent body fracture or the presence of kyphotic angulation, were not observed in this study. Moreover, vertebrography procedure was not performed, which is another limitation of this study.

\section{CONCLUSION}

Considering the patients' surgical risks and general conditions, $\mathrm{PV}$ is an effective, low-risk procedure for geriatric patients with vertebral burst fractures. Patients' activity levels and pain improved immediately after vertebroplasty. PV may be an alternative method for treating thoracolumbar burst fractures to prevent major surgical complications. Moreover, it helps patients achieve early mobilization and pain relief.

\section{ACKNOWLEDGEMENT}

Preparation for publication of this article is partly supported by Turkish Neurosurgical Society.

\section{REFERENCES}

1. Been HD, Bouma GJ: Comparison of two types of surgery for thoraco-lumbar burst fractures: Combined anterior and posterior stabilisation vs. posterior instrumentation only. Acta Neurochir (Wien) 141(4):349-357, 1999

2. Galibert P, Deramond H, Rosat P, Le Gars D: Preliminary note on the treatment of vertebral angioma by percutaneous acrylic vertebroplasty. Neurochirurgie 33(2):166-168, 1987

3. Ghobrial GM, Maulucci CM, Maltenfort M, Dalyai RT, Vaccaro AR, Fehlings MG, Street J, Arnold PM, Harrop JS: Operative and nonoperative adverse events in the management of traumatic fractures of the thoracolumbar spine: A systematic review. Neurosurg Focus 37(1):E8, 2014

4. Hitchon PW, He W, Viljoen S, Dahdaleh NS, Kumar R, Noeller $\mathrm{J}$, Torner J: Predictors of outcome in the non-operative management of thoracolumbar and lumbar burst fractures. $\mathrm{Br}$ J Neurosurg 28(5):653-657, 2014

5. Hiwatashi A, Westesson PL: Vertebroplasty for osteoporotic fractures with spinal canal compromise. AJNR Am J Neuroradiol 28(4):690-692, 2007

6. Huet H, Cabal P, Gadan R, Borha A, Emery E: Burst-fractures and cementoplasty. J Neuroradiol 32(1):33-41, 2005

7. Jacobs RR, Asher MA, Snider RK: Thoracolumbar spinal injuries. A comparative study of recumbent and operative treatment in 100 patients. Spine (Phila Pa 1976) 5(5):463-477, 1980

8. Krüger A, Zettl R, Ziring E, Mann D, Schnabel M, Ruchholtz $\mathrm{S}$ : Kyphoplasty for the treatment of incomplete osteoporotic burst fractures. Eur Spine J 19(6):893-900, 2010 
9. Lapras C, Mottolese C, Deruty R, Lapras C Jr, Remond J, Duquesnel J: Percutaneous injection of methyl-metacrylate in osteoporosis and severe vertebral osteolysis (Galibert's technic). Ann Chir 43(5):371-376, 1989

10. Lieberman IH, Togawa D, Kayanja MM: Vertebroplasty and kyphoplasty: Filler materials. Spine J 5 Suppl 6:305S-316S, 2005

11. Nakano M, Hirano N, Matsuura K, Watanabe H, Kitagawa $\mathrm{H}$, Ishihara $\mathrm{H}$, Kawaguchi $\mathrm{Y}$ : Percutaneous transpedicular vertebroplasty with calcium phosphate cement in the treatment of osteoporotic vertebral compression and burst fractures. J Neurosurg 97 Suppl 3:287-293, 2002
12. Prather H, Watson JO, Gilula LA: Nonoperative management of osteoporotic vertebral compression fractures. Injury 38 Suppl 3:S40-48, 2007

13. Ross PD: Clinical consequences of vertebral fractures. Am J Med 103(2A):30S-42S, 1997

14. Schmidt R, Cakir B, Mattes T, Wegener M, Puhl W, Richter M: Cement leakage during vertebroplasty: An underestimated problem? Eur Spine J 14(5):466-473, 2005

15. Shin JJ, Chin DK, Yoon YS: Percutaneous vertebroplasty for the treatment of osteoporotic burst fractures. Acta Neurochir (Wien) 151(2):141-148, 2009 